\title{
Introduction: Some Reflections on the York Project
}

\author{
Alan Blum and Peter McHugh \\ York University
}

\section{The Institution of Childhood}

If childhood was a social fact in Durkheim's sense we might get the impression that it was one of those external and coercive "things" situated in some exterior space to us. But Durkheim ${ }^{1}$ says of the social fact:

It consists of ways of acting, thinking and feeling external to the individual and endowed with a power of coercion by reason of which they control him.

Let us be careful here, as we speak of these "facts," childhood as "ways of thinking and feeling external" to individuals. It is these coercive ways or facts which exist in society as social facts and which, because we are in society, are external and coercive to us. Our common ways of thinking and feeling, our practices,

should not be confused with biological phenomena since they consist of representations and of actions.

Childhood as a social fact, as a social phenomenon, refers to these representations and actions, these ways of thinking and feeling, that organize the notion of childhood. Society represents and enacts these "ways of thinking and feeling" as institutions which become for us social facts, e.g., the social fact of childhood.

Now we are free of the aspiration to predicate of childhood as if it was a substantive for if it refers to ways - in part, to our ways - of thinking and feeling, this institution names a collection of practices, a virtual system. If we privilege any part of the system, e.g., the behavior of children, we risk forgetting that it is a whole.

These external and coercive representations and actions which are institutions for all of us as members of society become for those of us who take the reflective turn, the systems which are discernable in our institutions, the systems which we approach as social facts.

We entertain no semiotic fantasies here: we only suggest that what we originally and naively approach as our institutions are implicated systematically in assumptions and consequences; our actions and representations of children and of childhood reveal to theorizing systematic implications.

We represent these implications (the implications of our actions and representations) through the device of "culture" as, for example, in saying of the social fact of childhood, that it forms a children's culture. This is how we represent the systematic implications of our common social representations, our institution of childhood. Again, children's culture does not privilege the representations of children's behavior for it is intended to formulate systematic implications of enacting and representing childhood.

If Durkheim says of our ways of acting, thinking and feeling that they "consist of representations and of actions" he must mean that our actions enact our ways of thinking and feeling, that an enactment is nothing less than a re-enactment of ways of thinking and feeling and so, a representation. In this way the actions of society with respect to childhood can be un- 
derstood as the actions of representing its thinking and feeling with respect to childhood.

For us what is important is that society can be understood as enacting its thoughts and feelings in representations. Children's culture begins to point to the systematic implications of such re-enactments, such collective representations.

\section{The Problem of Childhood as Upbringing}

Childhood becomes problematic for adults insofar as the raising of children becomes a problem. We do not mean that all adults everywhere continuously reflect upon the raising of children; only that we envision the encounter of adult and child as an occasion for raising the question of upbringing as a theoretic problem for any self-reflective community, regardless of whether a community does reflect on its child-rearing in each particular case.

A tacit but decisive subscription to some conception of upbringing-of its character and end-thus needs to be seen as animating all relations to the notion of childhood. The problem of children reflects our conception of the requirements which underlie any mature encounter with the notion of childhood as a notion. ${ }^{2}$

The adult who personifies the self-reflective community is treated as if he orients to a standard of upbringing which he seeks to please through his practices. It is necessary and desirable for our work to understand the actor as orienting to a standard even though particular concrete individuals may deny such an orientation or its influence on any particular occasion.

We are not unique in our emphasis upon the problem of childhood as a theoretic interest of adults. Since it is often said that every "social fact" is a result of constructive activity, it is no surprise to assert the socially constructed character of childhood. But if, as Socrates says, to assert such a thing is not so wonderful, ${ }^{3}$ we must be careful to show how our work references a deeper need than to assert that childhood is simply constructed achievement or accomplishment.

The central assertion of our work is that the relation of adult to child is a relation of speaker to language which needs to be conceived as encompassing more than "interpretation" or "construction" because it is organized around an orientation of moral respect to language as good in-itself. In this sense our work will seek to develop the notion of childhood in-itself as a notion that is unlike any other because we seek a notion which is essential to the understanding of childhood in itself.

If we can agree that caring for youth is a fundamental problem faced by the community, we can also agree that any rational and responsible approach to the problem represents a theoretic solution on the part of the community to the requirements of moral education. 


\section{The Collective Representation of Upbringing as Part of the Communal Story}

Any such solution has its source in a communal self-definition of what it is and of where it is going, of its nature and ends. This communal selfdefinition is affirmed and repeated in ordinary social actions which attempt to influence its acceptance by parents and offspring, for example, in teaching, drawing up curricula, advising parents, and creating desirable environments.

In studying the relationship between social theory and the notion of childhood we are investigating how this relationship is mediated by the community. Answers to such questions are drawn from an examination of the way(s) in which the community exhibits itself in its range of ongoing and ordinary social practices, particularly in its relation to its offspring.

In mundane social practices the community shows how it conceives of childhood and how it formulates the issues raised by childhood as a problem for its own collective status. That childhood is seen in the way it is means that it is theorized, and that its recognition as a problem is inseparable from the conceptual and linguistic procedures through which it becomes intelligible to the community.

Therefore the theoretic actor serving as the focus of our research is the community as such, the community which, in conceiving of childhood as a problem, advances varieties of questions and answers to address that problem, and varieties of theory and method to resolve the issues posed by that problem.

The community most vividly shows its particular theoreticity -whether it leans toward technical or moral conceptions of childhood for example-through its ordinary dealings with children, such as their routine nurturance and instruction and the development of plans for their pleasure and entertainment.

Our study of the ways in which society relates to its children permits us to approach the deep issues of upbringing and moral education which apply to everyone and not just to children. Our interest is broader than, but includes, the interests that usually direct work on education and socialization.

\section{Methods}

It should be stressed that our research method is not distinct from our research aim, as if our practice could be segregated from our theory. In fact, our work is generally grounded in the principled integrity of theory and practice; we could not think of our research method independently of the community of conversationally engaged teachers and students from which it comes and of which it would be an example. The various topics we outline are only differences in usage, and while we respect and attempt to sustain such difference we must do so by caring for our tradition as the integral source of this respect.

The issues of self-reflection which we represent in this work are then invitations to reflect upon them from within the community of our tradition. 
Our research aim is to exemplify and represent our tradition in our usage and our research strategy (the way we care for our usage) does (should, will) exemplify our tradition in practice.

Our actual research method seeks to become conversation, to become teaching, because we try to excavate and formulate what is essential-the principle-in some topic. We do this by continuous inquiry into the rehearsal of the usages we are able to generate as the intelligible practices which constitute the topic. These usages are regions of practice, regions which are communalized by our own formulation of their deep need, their orientation. Several kinds of conversation proceed simultaneously in the course of our work: (1) that between the analysis and the topic (between theory and practice); (2) that between members of the community doing the analysis (between inquirers); (3) that between the community and its tradition (between our speech and language). Our practices-methodare interactive and collaborative, and take the form of a dialogue between those engaged in analysis:

One way to formulate our collaboration is through the standard terms of "ego" and "alter." Ego, for us, is the speaker who, by speaking, necessarily forgets his reason for speech. Alter reminds ego why he speaks by formulating ego's auspices. In this way, alter makes it rational for ego to speak. (McHugh, Raffel, Foss, \& Blum, 1974, p. 4)

More concretely, our procedure was developed as an icon of conversation:

The first step is for one of us to write up some of our material (even before this stage, however, there has been extensive interchange in working up ideas to the point they can be written about).... Everyone then writes a response in the form of another whole and self-contained paper (not just a set of notes or suggestions). These responses are distributed to the whole group and they are discussed, in conjunction with the original. Then someone edits the full collection of material into a "finished" paper. (McHugh, Raffel, Foss, \& Blum, 1974, pp. 4-5)

For us, conversation is the essential principled practice and it is this which we hope the analysis of any particular topic would exhibit and enhance, and without which no inquiry would be possible. We would not undertake to do analysis except under the theoretic auspices of principled conversation, and it is these auspices we seek to display and to teach through the practice of dialogic interaction.

Our deep need is thus for conversation that invites and reveals the reachievement of communal inquiry. Conversation takes form between the inquirer and material, among inquirers themselves, and within the inquirer's work as a reformulation of the tradition that inquiry represents. Although conversation has a subject in that it can be topical, what conversation is is the practice of community. In this respect, then, we would formulate any conversational community as a teaching community because conversation seeks to reachieve and speak from the principled centre of the communal lifeworld. ${ }^{4}$

It has been said that the only difference between teacher and student is the former's greater willingness to learn. This is a subtle irony, however, because no student could be entirely resistant and remain a student. Certainly a committed student takes very great though different risks which seem at times to constrain the student, for the student must undertake to 
learn. That is, the student must accept the need for conversation "in principle" while at the same time he is unqualified for conversation: (1) He desires to converse without knowing the "procedure" (method) of conversation. (2) He treats that desire as moral and the risk as therefore worth taking. The student, thus, knows the principle of conversation (that it is good) but not its rules. The teacher is engaged simultaneously (a) in conversation (b) with those who are unqualified to converse.

Of course it would be impossible to become qualified, even after showing the desire to undertake, unless the community made true conversation accessible, and this is the interest of the teacher as one who nurtures the desire for conversation among the unqualified. Thus "children's culture" consists in conversation constituted within the unqualified-qualified relation. Children's rights, for example, would here be: (1) the necessity that community display to the unqualified the commitment to undertake to become qualified; (2) the necessity of the community to undertake to teach the unqualified as a conversational response to their desire to undertake. This is to say that the teacher is an example of the moral good of undertaking and a formulator of the practices of qualification which are guided by this desire. Such teaching is the educational equivalent of the communal belief in the good of integration as the good of bringing the practices of community together: to nurture and bring together those who are qualified and those who are not, and to re-formulate the good of such a relation by bringing it together with its tradition of principled speaking. In our view, all class work, all research, all writing-all interaction within the learning community-orients to this need. Furthermore, it would only be through such orientation to principle that the interactional dialogues of methodic practice could be seen to express dialectic movement between the speech of interaction and the language of communal principle. We have attempted in our examination of self-reflection to express and formulate how topic and method are integral to one another as regions of speaking practice, which are collected into community by conversation in the tradition of language.

\section{The Studies}

Our analysis requires that we begin with received opinions on the rearing of children and through an examination of such opinions, move to re-lay their ground in the conventions of men. Our interest lies in examining the embodiment of such conventions and assumptions about education and childhood that are continuously and essentially in need of clarification and inquiry.

This movement, from the opinions to the conventions which support the opinions and endow them with their reasonable character, is only a beginning: we want to resist the cynical or relativist temptation to end at that point. Ultimately we need to question the excellence of various conventions because of our belief that the desire to question excellence is what opens the mundane life to theorizing.

It might seem paradoxical for research on childhood to conceive of its subject (the practical actor) as the adult rather than the child but this choice will become more intelligible as our analysis develops. 
Policies and decisions concerning children ultimately derive from conceptions of childhood. Those who make such decisions must premise their choice of ideas about children's needs and capacities, how these change with age, what circumstances are good or bad for growing children, and some notion of where to draw the line between childhood and adulthood. These beliefs are not usually stated explicitly; most often they are tacitly assumed. (Skolnick, 1975)

We conceive of a process of theorizing as re-collecting our discursive practices (with children) as if these practices were exemplary parts of a language. For example, the idea of Bildung (self-formation, self-cultivation) permits us to approach the language in which children are formulated and addressed as a text which is controlled in decisive (if often tacit) ways by conceptions of what is good for the cultivation and formation of character. In the same way, language can be understood as controlled in decisive and often tacit ways by conceptions of what is needed for good speech (whether, for example, good speech is seen as intelligible, powerful, exact, resonant, etc.).

As language, our relationships to our offspring appear as a decisive form of life with their own rationalities, grammar and rules of intelligibility. Self-reflection upon language will then be exemplified in this particular case as an enterprise which seeks to theorize about the ways in which practices of speaking about children are limited by and grounded in particular circumstances and deep needs and conventions for discussing the needs, limits and capacities of children.

Each of the studies that follow uses in its way some part of the communal discourse on childhood as the occasion to contemplate the nature and influence of parental intervention in the life of the child. This discourse appears first in the multitude of usages concerning what is right and wrong for children, what they need and want, what will amuse, entertain and enlighten them, how to improve them, cultivate their minds and bodies, construct policy on their behalf and conduct research on them. Such ways and means of "acting, thinking and feeling" form, as we have said, a virtual system for those with a theoretic interest in the discourse on childhood.

In this issue of Phenomenology + Pedagogy, we start to identify the "highlights" of such ways and means, only intermittently and implicitly hinting at their systematic implications. For example, all of the studies in this special theme section suggest the indispensible link between representations of childhood and the conception of upbringing; yet, there is no concerted explication of the notion of childhood beyond the point of developing its content through the ideas of care and cultivation evoked by the conception of Paideia. In a forthcoming publication we formulate Paideia itself as but a surface feature of the communal interest in justice and natality.

\section{Acknowledgements}

The York research project on children's culture was one-fourth of a research programme funded by the Social Sciences and Humanities Research Council, Grant No. 431-77006, done in collaboration with principal investigators from the Ontario Institute for Studies in Education who did not participate in our work and are not responsible for our findings. We would like to acknowledge the organizational collaboration of Professors James Heap, Dieter Misgeld and Ronald Silvers for their support and generosity in many ways. 


\section{Notes}

1. Emile Durkheim, The Rules of Sociological Method. Glencoe, IL: The Free Press, 1950.

2. We say, following Hegel, that the mature encounter with language seeks to confront the notion in-itself.

3. See his reaction to Zeno's proposition that one thing can be many and many things can be one in the Parmenides.

4. We mean to include all conversational communities and not just those which are formally stipulated as educational (Blum \& McHugh, 1978, pp. 1-17).

\section{References}

Blum, A., \& McHugh, P. (1978). Introduction. In A. Blum \& P. McHugh, (Eds.), Friends, enemies and strangers: Studies in theorizing in art, science and everyday life.

McHugh, P., Raffel, S., Foss, D., \& Blum, A. (1974). On the beginning of social inquiry. London and Boston: Routledge and Kegan Paul.

Skolnick, A. (1975, Summer). The limits of childhood: Conceptions of child development and social context. Law and Contemporary Society. 